Rabaska

Revue d'ethnologie de l'Amérique française

\title{
Roger Matton (1929-2004)
}

\section{Centre de musique canadienne}

Volume 2, 2004

URI : https://id.erudit.org/iderudit/201652ar

DOI : https://doi.org/10.7202/201652ar

Aller au sommaire du numéro

Éditeur(s)

Société québécoise d'ethnologie

ISSN

1703-7433 (imprimé)

1916-7350 (numérique)

Découvrir la revue

Citer ce document

Centre de musique canadienne (2004). Roger Matton (1929-2004). Rabaska, 2,

157-157. https://doi.org/10.7202/201652ar

Ce document est protégé par la loi sur le droit d'auteur. L'utilisation des services d'Érudit (y compris la reproduction) est assujettie à sa politique d'utilisation que vous pouvez consulter en ligne.

https://apropos.erudit.org/fr/usagers/politique-dutilisation/
Cet article est diffusé et préservé par Érudit.

Érudit est un consortium interuniversitaire sans but lucratif composé de l'Université de Montréal, l'Université Laval et l'Université du Québec à Montréal. Il a pour mission la promotion et la valorisation de la recherche. https://www.erudit.org/fr/ 


\section{Nécrologie}

\section{Roger Matton (1929-2004)}

Né à Granby (Québec) en 1929, Roger Matton étudie la composition au Conservatoire de musique du Québec, à Montréal, avec Claude Champagne (1945) et à l'École normale supérieure de musique, à Paris, avec Nadia Boulanger (1950-1955); il fréquente aussi au Conservatoire la classe d'analyse d'Olivier Messiaen. Au Canada, après un stage d'apprentissage avec l'ethnologue Marius Barbeau, il entre en 1956 aux Archives de folklore de l'université Laval, à titre de professeur, recherchiste et ethnomusicologue.

La réputation de Roger Matton, tant au Canada qu'aux États-Unis et en Europe, est solidement établie. Déjà, en 1962, l'Orchestre symphonique de Montréal lui commandait le

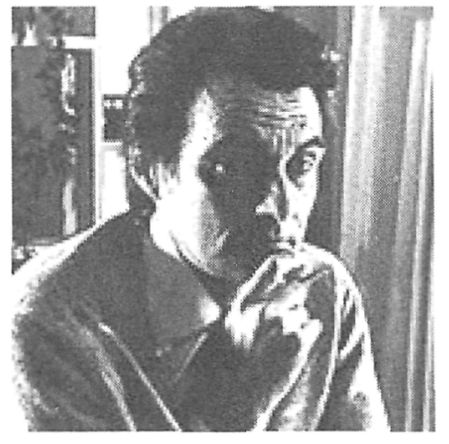
Mouvement symphoniqe 11 pour représenter le pays lors d'une tournée en France, en Autriche et en Russie. En 1960, le public de New-York découvrait grâce à Wilfrid Pelletier le ballet L'Horoscope. Le Mouvement symphonique $I$ connut le succès à Paris en 1963 et le Te Deum fut créé en première européenne et enregistré dans la capitale française en mai 1969. De 1960 à 1978, quatre œuvres sont sorties de sa période dite mouvement symphonique, montrant ainsi son intérêt pour les grands effectifs et les espaces amples.

Plusieurs prix et honneurs jalonnent la carrière de Matton. En 1965, le Prix de la création musicale lui est décerné lors du Gala des artistes, pour ses œuvres présentées à l'émission de télévision «L'Heure du concert » à RadioCanada. En 1966, il obtient le Prix du disque (Pierre Mercure) pour l'enregistrement de son Concerto pour deux pianos et orchestre. En 1969, le Prix de musique Calixa-Lavallée et la médaille Bene Merenti de Patria lui sont décernés, pour l'ensemble de son œuvre, par la Société Saint-Jean-Baptiste de Montréal. En 1987, Radio-Canada international publie un coffret de quatre disques de ses œuvres (ACM29). En 1984, Roger Matton est décoré Officier de l'Ordre du Canada. Il est décédé le 7 juin 2004 des suites d'une longue maladie.

Source : Centre de musique canadienne, Montréal www.cmcquebec.ca 